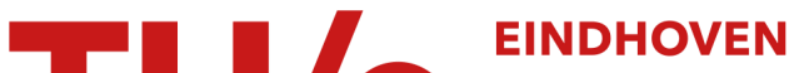 UNIVERSITY OF TECHNOLOGY
}

\section{Dynamic ellipsometric porosimetry investigation of permeation pathways in moisture barrier layers on polymers}

Citation for published version (APA):

Perrotta, A., Kessels, W. M. M., \& Creatore, M. (2016). Dynamic ellipsometric porosimetry investigation of permeation pathways in moisture barrier layers on polymers. ACS Applied Materials \& Interfaces, 8(38), 25005-25009. https://doi.org/10.1021/acsami.6b08520

\section{Document license:}

TAVERNE

DOI:

10.1021/acsami.6b08520

Document status and date:

Published: 12/09/2016

\section{Document Version:}

Publisher's PDF, also known as Version of Record (includes final page, issue and volume numbers)

\section{Please check the document version of this publication:}

- A submitted manuscript is the version of the article upon submission and before peer-review. There can be important differences between the submitted version and the official published version of record. People interested in the research are advised to contact the author for the final version of the publication, or visit the $\mathrm{DOI}$ to the publisher's website.

- The final author version and the galley proof are versions of the publication after peer review.

- The final published version features the final layout of the paper including the volume, issue and page numbers.

Link to publication

\section{General rights}

Copyright and moral rights for the publications made accessible in the public portal are retained by the authors and/or other copyright owners and it is a condition of accessing publications that users recognise and abide by the legal requirements associated with these rights.

- Users may download and print one copy of any publication from the public portal for the purpose of private study or research.

- You may not further distribute the material or use it for any profit-making activity or commercial gain

- You may freely distribute the URL identifying the publication in the public portal.

If the publication is distributed under the terms of Article $25 \mathrm{fa}$ of the Dutch Copyright Act, indicated by the "Taverne" license above, please follow below link for the End User Agreement:

www.tue.nl/taverne

Take down policy

If you believe that this document breaches copyright please contact us at:

openaccess@tue.nl

providing details and we will investigate your claim. 


\title{
Dynamic Ellipsometric Porosimetry Investigation of Permeation Pathways in Moisture Barrier Layers on Polymers
}

\author{
Alberto Perrotta, ${ }^{*}, \neq$ Wilhelmus M. M. Kessels, ${ }^{\dagger, \S}$ and Mariadriana Creatore ${ }^{*},, \S$ \\ ${ }^{\dagger}$ Department of Applied Physics, Eindhoven University of Technology, 5600 MB Eindhoven, The Netherlands \\ ${ }^{\ddagger}$ Dutch Polymer Institute (DPI), 5600 AX Eindhoven, The Netherlands \\ ${ }^{\S}$ Solar Research SOLLIANCE, High Tech Campus 21, 5656 AE Eindhoven, The Netherlands
}

Supporting Information

ABSTRACT: The quality assessment of moisture permeation barrier layers needs to include both water permeation pathways, namely through bulk nanoporosity and local macroscale defects. Ellipsometric porosimetry (EP) has been already demonstrated a valuable tool for the identification of nanoporosity in inorganic thin film barriers, but the intrinsic lack of sensitivity toward the detection of macroscale defects prevents the overall barrier characterization. In this contribution, dynamic EP measurements are reported and shown to be sensitive to the detection of macroscale defects in $\mathrm{SiO}_{2}$ layers on polyethylene naphthalate substrate. In detail, the infiltration of probe molecules, leading to changes in optical properties of the polymeric substrate, is followed in time and related to permeation through macroscale defects.

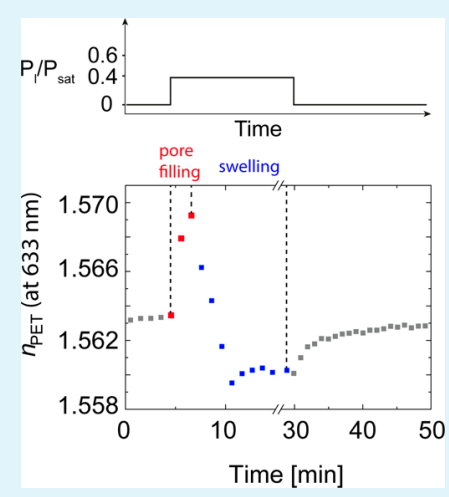

KEYWORDS: dynamic ellipsometric porosimetry, permeation barriers, macro-scale defects, nanoporosity, $\mathrm{PE}-\mathrm{CVD}, \mathrm{SiO}$

$\mathrm{O}$ ne of the main advantages of organic electronics devices relies on their development on flexible substrates. However, moisture permeation barrier layers are necessary to block water and oxygen from diffusing in the device. ${ }^{1,2}$ Barriers can be either directly deposited on flexible devices or on flexible foils, subsequently used for device encapsulation. This contribution specifically relates to the investigation of the quality of barriers deposited on flexible substrates. The permeation of water vapor through single inorganic layers is known to occur through two main pathways, macroscale defects (ranging from tens of nanometers to hundreds of micrometers in size) and nanopores (ranging from the water kinetic diameter, $0.27 \mathrm{~nm}$, to roughly few $\mathrm{nm}$ ). ${ }^{3,4}$ We have previously ${ }^{5}$ categorized the barrier quality of a layer as intrinsic when permeation through nanopores is considered, whereas we refer to the effective barrier quality when including permeation through local macro-scale defects. These defects are often generated during the deposition process or due to particles' contamination on the substrate surface. The control and detection of both permeation pathways is the key to the overall barrier quality evaluation. Recently, we have shown that ellipsometric porosimetry (EP) is a valid methodology for detection and classification of the nanoporosity $(0.27-2 \mathrm{~nm})$, controlling the intrinsic barrier properties of inorganic thin films. ${ }^{5-7}$ In EP, the uptake of a probe molecule in the pores of the barrier is monitored by spectroscopic ellipsometry (SE) as a function of its partial pressure, in turn providing information on its porosity and pore size range. ${ }^{8-10}$ However, our investigations have also shown that this methodology is not sensitive toward detection of macroscale defects. ${ }^{6,11}$ Because of the large surface area characterizing the defect, the probe molecule adsorption leads to incomplete filling of the defect volume, this latter being necessary to induce changes in the refractive index of the layer.

However, the EP methodology may become sensitive to the detection of macroscale defects in case of barriers deposited on substrates optically sensitive to the probe molecule permeation. Hence, in this contribution, we will explore the possibility of identifying, by means of time-resolved EP (dynamic EP), macroscale defects in inorganic barriers deposited on polymers. When successful, this approach would allow the characterization of the barrier layer (quality) deposited directly on polymers, therefore providing a highly valuable tool to evaluate barrier foil systems for device encapsulation.

One of the polymers most commonly used as substrate in flexible electronics is polyethylene 2,6-naphthalate (PEN), because of its intrinsic water permeation barrier performance $\left(\right.$ WVTR $\left.\approx 1 \times 10^{-1} \mathrm{gm}^{-2} \mathrm{day}^{-1}\right)$, flexibility, and relatively high glass-transition temperature. ${ }^{12}$ PEN foils, however, often exhibit optical anisotropy, ${ }^{13}$ complex to model when monitoring adsorption-based processes, such as EP. Furthermore, PEN intrinsic barrier properties would lead with EP to rather long measurement time to detect significant changes in refractive index. Therefore, to tackle these practical challenges, we here

Received: July 12, 2016

Accepted: September 12, 2016

Published: September 12, 2016 
a)

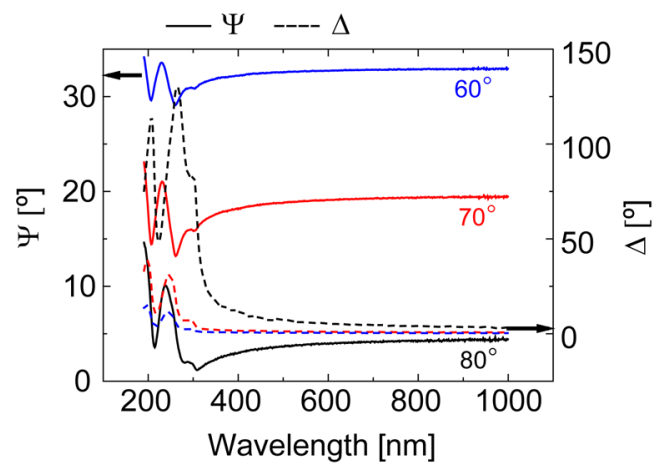

b)

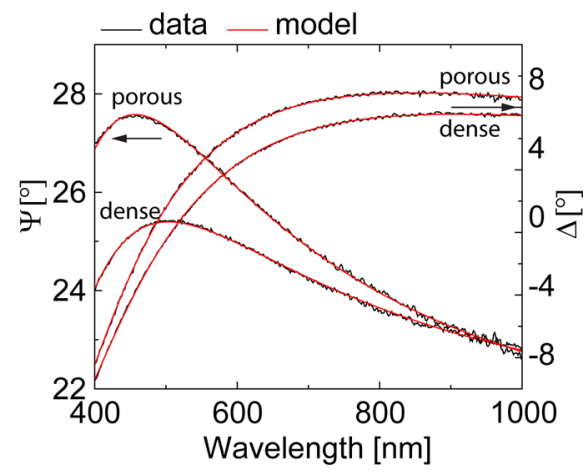

Figure 1. SE data $(\Psi, \Delta)$ of (a) free-standing PET foil, at three angles of incidence $\left(60,70,80^{\circ}\right)$; (b) porous and dense $100 \mathrm{~nm}$ thick PE-CVD $\mathrm{SiO}_{2} /$ PET samples, measured at $70^{\circ}$.

considered amorphous, low density, optically isotropic polyethylene terephthalate (PET, Goodfellow, $250 \mu \mathrm{m}$ thick). The optical properties of free-standing PET foils have been characterized a priori with SE. The measurements were performed in air at three angles of incidence $\left(60,70,80^{\circ}\right)$ in a wavelength range of $190-1000 \mathrm{~nm}$. To measure in reflection mode, the back side of the samples was mechanically scratched to minimize any possible reflection at the back side.

In Figure 1a, the SE data $(\Psi$ and $\Delta)$ are reported as a function of wavelength. The optical properties of the amorphous PET have been determined only in its transparent region, i.e., 400-1000 $\mathrm{nm}$. The dispersion relation chosen to describe the optical behavior of the polymer is the Cauchy function (cfr. Supporting Information). The $n$ values were found to be in the range $1.545-1.578$ (at $632.8 \mathrm{~nm}$ ) with an accuracy of \pm 0.003 , in agreement with the values found in the literature and those provided by the supplier. ${ }^{14}$ Differences in the PET refractive index are attributed to inhomogeneity in film density within the same batch. To model the surface roughness, a Bruggeman effective medium approximation (BEMA) layer ( $50 \%$ polymer, $50 \%$ voids) has been used to account for the polymer surface roughness, which is found in the range 1.5-3 $\mathrm{nm}$.

Plasma-enhanced chemical vapor deposition (PE-CVD) of $\mathrm{SiO}_{2}$ layers on PET substrates has been carried out in a homebuilt RF parallel plate capacitively coupled reactor (Figure 1b). ${ }^{15}$ The substrate temperature was set at $80{ }^{\circ} \mathrm{C}$. The plasma power was varied as to yield $\mathrm{SiO}_{2}$ layers with different mass density and, therefore, optical properties. $\mathrm{The}^{\mathrm{SiO}_{2}}$ layers have also been deposited on a $c$-Si substrate as reference. Two cases have been investigated, a $\mathrm{PE}-\mathrm{CVD} \mathrm{SiO}_{2}$ layer showing a dense matrix (dense $\mathrm{SiO}_{2}$ ) and one with a higher degree of porosity (porous $\mathrm{SiO}_{2}$ ). In Figure $1 \mathrm{~b}$, the ellipsometric data acquired ex situ, (i.e., after exposure to air) are reported as a function of the wavelength for the $100 \mathrm{~nm}$ thick PE-CVD $\mathrm{SiO}_{2} / \mathrm{PET}$ samples. The angle of acquisition $\left(70^{\circ}\right)$ was chosen according to the fixed angle stage of the EP setup. For the PE-CVD $\mathrm{SiO}_{2} / \mathrm{PET}$ samples, the ellipsometry data were modeled adopting two Cauchy functions, representing the PET substrate and $\mathrm{SiO}_{2}$ layer. The refractive index values for the layers deposited on PET and $c$-Si are reported in Table 1, showing similarities in the bulk properties of layers grown on different substrates. The difference in refractive index between the $\mathrm{SiO}_{2}$ layer and PET is sufficient to independently follow events occurring in the two layers due to the limited amount of parameters modeled. Furthermore, a correlation matrix calculated from the model
Table 1. Refractive Index Values of the Layers/Substrates under Investigation

\begin{tabular}{c|c|c|c|c|c|c|c}
\hline \hline \multicolumn{3}{c|}{ Dense $\mathrm{SiO}_{2}$} & \multicolumn{4}{c}{ Porous $\mathrm{SiO}_{2}$} \\
\hline \multicolumn{3}{c}{ on PET } & on $\mathrm{Si}$ & \multicolumn{3}{c|}{ on PET } & on $\mathrm{Si}$ \\
\hline substrate & \multicolumn{2}{c}{$\mathrm{SiO}_{2}$} & $\mathrm{SiO}_{2}$ & substrate & \multicolumn{2}{c}{$\mathrm{SiO}_{2}$} & $\mathrm{SiO}_{2}$ \\
\hline \multirow{3}{*}{1.561} & ex-situ & vacuum & & & ex-situ & vacuum & \\
\cline { 2 - 5 } & 1.461 & 1.448 & \multirow{2}{*}{1.461} & 1.545 & 1.448 & 1.422 & \multirow{2}{*}{1.447} \\
\hline
\end{tabular}

variables excluded interdependency of the analysis parameters, confirming the goodness of the fit.

Once defined its optical properties, the pristine PET substrate has been then studied by dynamic EP. The EP measurements were carried out in a home-built porosimeter, described in detail elsewhere. ${ }^{7,11}$ Toluene ( $0.6 \mathrm{~nm}$ in diameter) is chosen as adsorptive, because of its nonpolar nature, making possible to exclude polar interactions during adsorption and desorption (e.g., hydrogen bond formation). Before the measurements, the samples were outgassed overnight in the porosimeter $\left(10^{-6} \mathrm{mbar}\right)$ at $30{ }^{\circ} \mathrm{C}$. To avoid adsorption of toluene on the back-side of the sample during the measurements, the sample holder is equipped with a connection to an Ar line. An O-ring is placed in contact with the back of the sample, creating a clearance not directly exposed to toluene vapors. A constant Ar flow prevents toluene from back-diffusing and adsorbing (Figure S1). The partial pressure of toluene is expressed as the ratio between its vapor pressure $\left(P_{1}\right)$ and saturation pressure $\left(P_{\text {sat }}\right)$ at the stage temperature $\left(30^{\circ} \mathrm{C}\right)$. In Figure 2, the variation of the refractive index of the PET substrate is reported as a function of time.

The toluene $P_{1} / P_{\text {sat }}$ was set at a value of 0.4 . Above this value, according to previous studies on barriers deposited on $c-\mathrm{Si}^{5}{ }^{5}$ all nanopores are completely filled by probe molecules (micropore filling phase), whereas the formation of a multilayer is rather limited. Therefore, this choice allows the comparison of samples having different nanoporosity content by monitoring the overall increase of refractive index in the $P_{1} / P_{\text {sat }}$ range $0-$ 0.4. At first, the refractive index increases due to the filling of the polymer free volume accessible to toluene. Subsequently, $n_{\text {PET }}$ abruptly decreases, reaching an equilibrium value below the refractive index measured in vacuum. The decrease in $n_{\mathrm{PET}}$ has been attributed to swelling occurring in the polymer due to adsorption of toluene. The permeant widens the free volume of the polymer, eventually decreasing its density. ${ }^{16,17}$ The swelling is however limited, in line with what reported in the literature for polymers exposed to organic vapors. ${ }^{18,19}$ A saturation is then reached, pointed out by the constant $n_{\mathrm{PET}}$ value $(10-30$ 


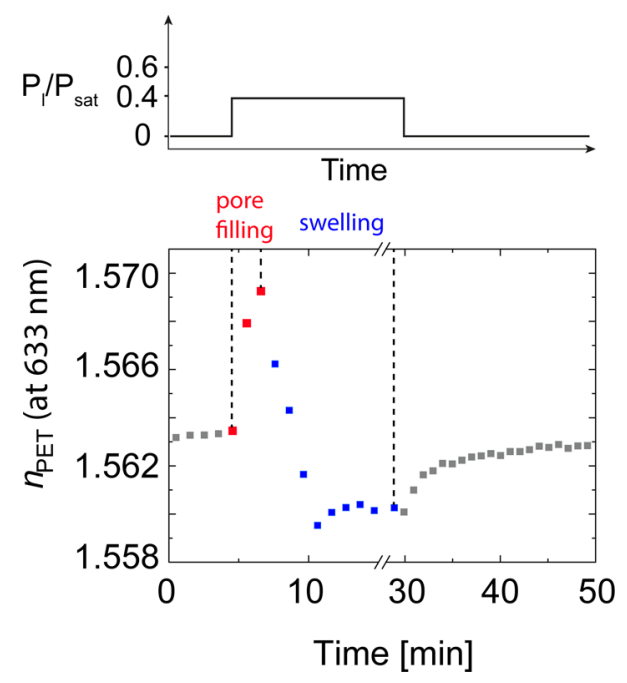

Figure 2. PET refractive index vs exposure time to toluene vapors.

min range). Finally, toluene $P_{1} / P_{\text {sat }}$ has been set to 0 to monitor its desorption and verify whether toluene adsorption caused irreversible structural changes in the polymer. The swelling is reversible, as witnessed by the recovery of $n_{\mathrm{PET}}$ at $P_{1} / P_{\text {sat }}=0$ (Figure 2). Therefore, as preliminary conclusion, PET is suitable to detect the probe molecule permeation in its free volume and different permeation phases can be discerned (pore filling/swelling).

In Figures 3 and 4, the dynamic EP studies on PET and PECVD $\mathrm{SiO}_{2}$ are reported. The $n$ value in vacuum (Table 1 ) differs from the ex situ counterpart because of desorption of water from the inorganic layer at low pressure. In Figure 3, the refractive index of both PET substrate and dense $\mathrm{SiO}_{2}$ are reported as a function of the exposure time to toluene vapors. At $P_{1} / P_{\text {sat }}=0.4$ (Figure $3 \mathrm{a}$ ), no significant changes have been measured upon toluene exposure, pointing out the absence of nanopores accessible to toluene. Similarly, the PET refractive index has undergone no changes, suggesting the absence of pathways accessible to toluene molecules. In order to verify this hypothesis, $\mathrm{P}_{1} / \mathrm{P}_{\text {sat }}$ was increased to 0.6 (Figure $3 \mathrm{~b}$ ). $n_{\mathrm{PET}}$ slightly increased, indicating toluene infiltration into its free volume. The value of $n_{\mathrm{SiO}_{2}}$ showed an increase up to $20 \mathrm{~min}$ of exposure, but within the measurement error and it was thus considered constant, showing no toluene uptake in the barrier layer. However, no swelling occurred, inferred by the saturation of the refractive index value after 25 min of exposure. Because of lack of detectable nanoporosity in the $\mathrm{SiO}_{2}$ layer, we can conclude that the adsorption of toluene in the PET free volume necessarily occurs through macro-scale defects. The constant value of the refractive index at $P_{1} / P_{\text {sat }}$ of 0.4 , the smaller increase in refractive index with respect to the pristine polymer (see Figure 2), and the absence of swelling in the PET substrate at $P_{1} / P_{\text {sat }}$ of 0.6 may be explained by very limited macroscale defects present in the barrier. Considering the thickness of the polymer substrate $(250 \mu \mathrm{m})$, when its surface is covered by an impermeable barrier, the amount of toluene required to induce a significant variation of the optical properties, is reached only after long exposure times, and, in turn, the time-scale investigated might not suffice in showing either infiltration in the free volume (at $P_{1} / P_{\text {sat }}$ of 0.4 ) or swelling (at higher values). In the literature, long exposure times are also showed to be necessary to fill the porosity of PE-CVD modified low- $k$ materials deposited on $c$-Si, supporting this hypothesis. ${ }^{16}$ Therefore, the introduction of a substrate sensitive to probe molecule infiltration allows the detection of macroscale defects when selecting a probe molecule not permeating the bulk nanoporosity of the barrier. The validity of the adopted approach is confirmed by probing the dense $\mathrm{SiO}_{2}$ layer with a molecule that can access its nanoporosity, i.e., water (diameter $0.27 \mathrm{~nm}$, Figure S2). The $n$ values of the barrier and the PET substrate increase due to the infiltration of water. Taking into account a similar density of macro-scale defects in the sample measured with toluene and the one measured with water, differences in the refractive index increase are due to the infiltration of water through nanopores with a diameter accessible to the probe molecule. With this approach, new possibilities for the analysis of barrier/polymer systems are revealed.

In Figure 4, the effect of toluene exposure on porous $\mathrm{SiO}_{2}$ is reported. At $P_{1} / P_{\text {sat }}$ of 0.4 (Figures $4 \mathrm{a}-\mathrm{b}$ ), an increase in $\mathrm{SiO}_{2}$ refractive index is observed, attributed to nanopore filling, with a detected porosity content of $0.4 \%$ for the $\mathrm{SiO}_{2}$ layer. When compared to a similar layer deposited on $c$-Si (Figure S2), the porosity probed at the same $P_{1} / P_{\text {sat }}$ is $\sim 2 \%$. Considering the similar refractive index for the porous $\mathrm{SiO}_{2}$ deposited on PET and $c$-Si substrates (Table 1 ), we can conclude that the lower $\mathrm{SiO}_{2}$ nanoporosity content detected in the case of the polymer substrate is due to the fact the permeable substrate impedes the
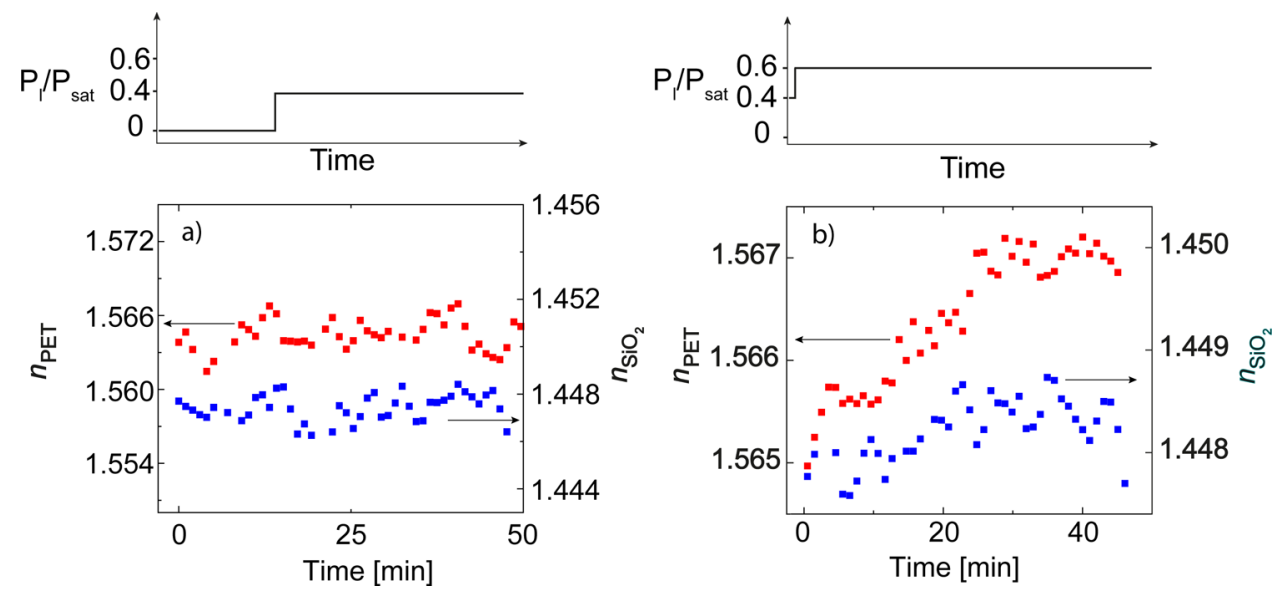

Figure 3. Dense $\mathrm{SiO}_{2} / \mathrm{PET}$ refractive index vs exposure time to toluene vapors at $P_{1} / P_{\text {sat }}$ of (a) 0.4 and (b) 0.6 . 

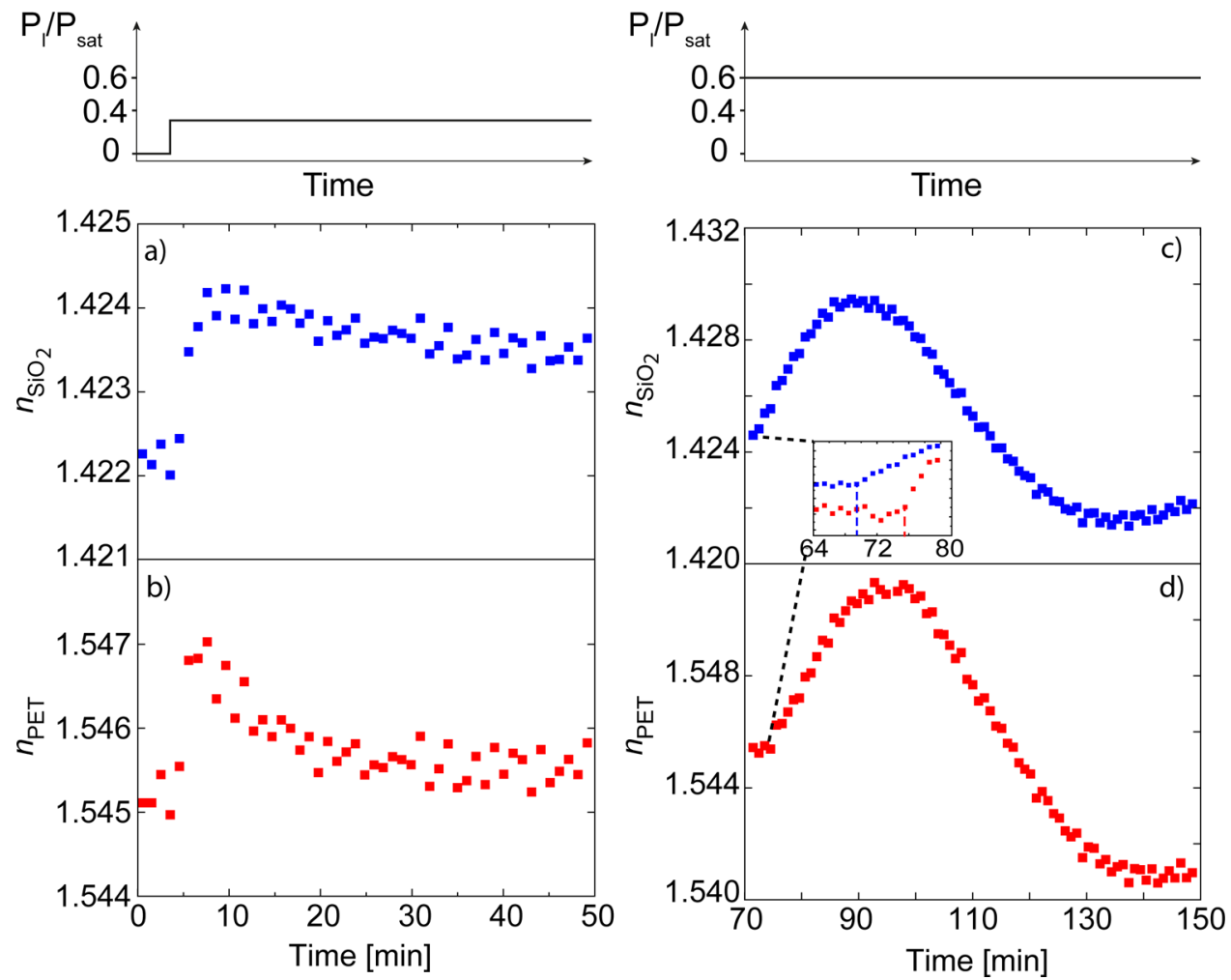

Figure 4. Refractive index vs time for porous $\mathrm{SiO}_{2}\left(n_{\mathrm{SiO}_{2}}\right.$, blue $)$ and PET $\left(n_{\mathrm{PET}}\right.$, red) at $P_{1} / P_{\text {sat }}$ of $(\mathrm{a}, \mathrm{b}) 0.4$ and $(\mathrm{c}, \mathrm{d}) 0.6$; in the inset, zooming of the delay in permeation at $P_{1} / P_{\text {sat }}$ of 0.6 .

pore filling to reach an equilibrium. The toluene diffuses through the nanoporosity toward the PET, impeding the whole characterization of the nanopore content in the barrier layer. In addition, the contribution of the diffusion through macroscale defects is present, since the PET refractive index increases simultaneously with the one of $\mathrm{SiO}_{2}$, upon exposure to toluene (pore filling phase). Subsequently, the pore-filling is followed by a limited swelling of the PET substrate, with respect to what observed in Figure 2, and this is certainly due to the presence of the barrier.

Although limited, the refractive index of $\mathrm{SiO}_{2}$ follows a similar trend. However, the changes are within the measurement error on the refractive index $( \pm 0.0005)$, and it is therefore constant. As in the case of the dense sample, the toluene partial pressure has been increased to 0.6 (Figures $4 \mathrm{c}, \mathrm{d}$ ). At first, the $\mathrm{SiO}_{2}$ refractive index immediately increases upon increase of the toluene vapor pressure. The maximum porosity filled is in the order of $1.4 \%, 0.6 \%$ lower than for similar barriers on $c-\mathrm{Si}$ (Figure S2). ${ }^{6}$ This suggests that by adopting higher partial pressures of the probe molecule it is possible to completely characterize the nanoporosity of inorganic layers on polymers. The PET pore filling is instead delayed of $6 \mathrm{~min}$ (inset in Figure $4 \mathrm{c}, \mathrm{d})$. Compared to the effect at $P_{1} / P_{\text {sat }}$ of 0.4 , where the increase in refractive index for the two layers occurs simultaneously, the permeation at 0.6 occurs mainly through the $\mathrm{SiO}_{2}$ nanoporosity, which might cause hindered toluene diffusion through the layer porosity and slower kinetics of permeation.

Finally, both PET and $\mathrm{SiO}_{2}$ refractive indexes decrease because of swelling in the polymer substrate, occurring when more toluene has permeated the barrier through both nanoporosity and macroscale defects. The refractive index of $\mathrm{SiO}_{2}$ reaches a value below the one in vacuum, inferring changes in the silica matrix (e.g., stress). However, in Figure 4c, $\mathrm{d}$, the refractive index of the barrier during the swelling phase was found to decrease earlier than the one of PET. This discrepancy can be explained as follows. The differences in thickness and therefore volume between the polymer $(250 \mu \mathrm{m})$ and the barrier film $(100 \mathrm{~nm})$ suggest that the amount of toluene needed to observe a variation in refractive index is rather different for the two layers. It is then reasonable to assume that swelling occurs in the polymer before than in the barrier (because of their chemical nature, inorganic vs organic) but we are not sensitive to the very early stage of this phenomenon when occurring only close to the polymer/barrier interface. When the swelling extends deeper throughout the polymer thickness, we are sensitive enough to see changes in the polymer refractive index. When comparing the polymer swelling in the $\mathrm{SiO}_{2} /$ PET system with the one occurred on the bare PET substrate, the $n_{\mathrm{PET}}$ variation is found in the same range. It can be argued that structural changes on the barrier layer caused by the polymer swelling allow toluene to permeate further in the PET substrate, accounting for the changes in $\mathrm{n}_{\text {PET }}$. However, the time for toluene to reach saturation is 1 order of magnitude slower than the one on the bare PET substrate, because of the presence of the $\mathrm{SiO}_{2}$ layer. When the PET swelling saturates, pointed out by a constant value in $n_{\mathrm{PET}}$, the $\mathrm{SiO}_{2}$ refractive index starts to increase, supposedly due to filling of the newly formed pores.

In summary, in this contribution dynamic EP has been demonstrated able to discern and follow the permeation of vapors through nanopores and macro-scale defects in barrier layers on polymers. The novelty of these results consists in the observation that the use of substrates sensitive to probe molecule permeation allows the diffusion to be followed through both pathways in inorganic barriers, giving indication 
of the kinetics and extent of permeation. However, the nanopore content cannot be fully characterized because of incomplete filling of the layer nanoporosity caused by the permeation through the polymeric substrate. Moreover, using probe molecules not penetrating the bulk nanoporosity of the layer, the detection of macroscale defects was achieved, overcoming the limitations of ellipsometry-based techniques. Therefore, EP is demonstrated valuable in the assessment of the overall quality of moisture permeation barriers.

\section{ASSOCIATED CONTENT}

\section{S Supporting Information}

The Supporting Information is available free of charge on the ACS Publications website at DOI: 10.1021/acsami.6b08520.

Experimental details on the deposition of the PE-CVD barriers; experimental details on the optical methods used to determine the optical properties of the layers, together with the definition of the optical model adopted; description of the ellipsometric porosimetry apparatus and basics of the technique; adsorption isotherm for a porous $\mathrm{PE}-\mathrm{CVD} \mathrm{SiO}_{2}$ deposited on $c$-Si; dense $\mathrm{SiO}_{2} / \mathrm{PET}$ refractive index vs exposure time to water vapors $(\mathrm{PDF})$

\section{AUTHOR INFORMATION}

\section{Corresponding Authors}

*E-mail: a.perrotta@tue.nl. Phone: +31402474095.

*E-mail: m.creatore@tue.nl.

\section{Author Contributions}

The manuscript was written through contributions of all authors. All authors have given approval to the final version of the manuscript.

\section{Funding}

This work forms part of the research program of the Dutch Polymer Institute (DPI) project \#752 of the Large Area Thin Film Electronics (LATFE) program.

\section{Notes}

The authors declare no competing financial interest.

\section{ACKNOWLEDGMENTS}

The authors thank J. J. A. Zeebregts, J. J. L. M. Meulendijks, and C. O. van Bommel (Eindhoven University of Technology) for their skillful technical assistance. M.C. acknowledges the Aspasia NWO program.

\section{REFERENCES}

(1) Park, J.-S.; Chae, H.; Chung, H. K.; Lee, S. I. Thin Film Encapsulation for Flexible AM-OLED: A Review. Semicond. Sci. Technol. 2011, 26 (3), 034001.

(2) Lewis, J. Material Challenge for Flexible Organic Devices. Mater. Today 2006, 9 (4), 38-45.

(3) Affinito, J.; Hilliard, D. A New Class of Ultra-Barrier Materials In Society of Vacuum Coaters 47th Annual Technical Conference Proceedings; Society of Vacuum Coaters: Materials Park, OH, 2004; pp 563-593.

(4) Roberts, A. P.; Henry, B. M.; Sutton, A. P.; Grovenor, C. R. M.; Briggs, G. A. D.; Miyamoto, T.; Kano, M.; Tsukahara, Y.; Yanaka, M. Gas Permeation in Silicon-Oxide/polymer ( $\mathrm{SiOx} / \mathrm{PET}$ ) Barrier Films: Role of the Oxide Lattice, Nano-Defects and Macro-Defects. J. Membr. Sci. 2002, 208 (1-2), 75-88.

(5) Perrotta, A.; van Beekum, E. R. J.; Aresta, G.; Jagia, A.; Keuning, W.; van de Sanden, M. C. M.; Kessels, W. M. M.; Creatore, M. On the Role of Nanoporosity in Controlling the Performance of Moisture
Permeation Barrier Layers. Microporous Mesoporous Mater. 2014, 188, 163-171.

(6) Perrotta, A.; García, S. J.; Creatore, M. Ellipsometric Porosimetry and Electrochemical Impedance Spectroscopy Characterization for Moisture Permeation Barrier Layers. Plasma Processes Polym. 2015, 12 (9), 968-979.

(7) Andringa, A.-M.; Perrotta, A.; De Peuter, K.; Knoops, H. C. M.; Kessels, W. M. M.; Creatore, M. Low-Temperature Plasma-Assisted Atomic Layer Deposition of Silicon Nitride Moisture Permeation Barrier Layers. ACS Appl. Mater. Interfaces 2015, 7 (40), 2252522532.

(8) Baklanov, M. R.; Mogilnikov, K. P.; Polovinkin, V. G.; Dultsev, F. N. Determination of Pore Size Distribution in Thin Films by Ellipsometric Porosimetry. J. Vac. Sci. Technol., B: Microelectron. Process. Phenom. 2000, 18 (3), 1385.

(9) Boissiere, C.; Grosso, D.; Lepoutre, S.; Nicole, L.; BrunetBruneau, A.; Sanchez, C. Porosity and Mechanical Properties of Mesoporous Thin Films Assessed by Environmental Ellipsometric Porosimetry. Langmuir 2005, 21 (26), 12362-12371.

(10) Dendooven, J.; Devloo-Casier, K.; Levrau, E.; Van Hove, R.; Sree, S. P.; Baklanov, M. R.; Martens, J. A.; Detavernier, C. In Situ Monitoring of Atomic Layer Deposition in Nanoporous Thin Films Using Ellipsometric Porosimetry. Langmuir 2012, 28 (8), 3852-3859.

(11) Perrotta, A.; García, S. J.; Michels, J. J.; Andringa, A.-M.; Creatore, M. Analysis of Nanoporosity in Moisture Permeation Barrier Layers by Electrochemical Impedance Spectroscopy. ACS Appl. Mater. Interfaces 2015, 7 (29), 15968-15977.

(12) Zardetto, V.; Brown, T. M.; Reale, A.; Di Carlo, A. Substrates for Flexible Electronics: A Practical Investigation on the Electrical, Film Flexibility, Optical, Temperature, and Solvent Resistance Properties. J. Polym. Sci., Part B: Polym. Phys. 2011, 49 (9), 638-648.

(13) Aresta, G.; Premkumar, P. A.; Starostin, S. A.; de Vries, H.; van de Sanden, M. C. M.; Creatore, M. Optical Characterization of PlasmaDeposited SiO2-Like Layers on Anisotropic Polymeric Substrates. Plasma Processes Polym. 2010, 7 (9-10), 766-774.

(14) Iiyama, K.; Ishida, T.; Ono, Y.; Maruyama, T.; Yamagishi, T. Fabrication and Characterization of Amorphous Polyethylene Terephthalate Optical Waveguides. IEEE Photonics Technol. Lett. 2011, 23 (5), 2010-2012.

(15) Aresta, G.; Palmans, J.; van de Sanden, M. C. M.; Creatore, M. Evidence of the Filling of Nano-Porosity in SiO2-like Layers by an Initiated-CVD Monomer. Microporous Mesoporous Mater. 2012, 151, 434-439.

(16) Puyrenier, W.; Rouessac, V.; Broussous, L.; Rébiscoul, D.; Ayral, A. Effect of Plasma Treatments on a Porous Low-K Material - Study of Pore Sealing. Microporous Mesoporous Mater. 2007, 106 (1-3), 40-48.

(17) Rouessac, V.; van der Lee, A.; Bosc, F.; Durand, J.; Ayral, A. Three Characterization Techniques Coupled with Adsorption for Studying the Nanoporosity of Supported Films and Membranes. Microporous Mesoporous Mater. 2008, 111 (1-3), 417-428.

(18) Ogieglo, W.; Wormeester, H.; Eichhorn, K.-J.; Wessling, M.; Benes, N. E. In Situ Ellipsometry Studies on Swelling of Thin Polymer Films: A Review. Prog. Polym. Sci. 2015, 42, 42-78.

(19) Ogieglo, W.; Upadhyaya, L.; Wessling, M.; Nijmeijer, A.; Benes, N. E. Effects of Time, Temperature, and Pressure in the Vicinity of the Glass Transition of a Swollen Polymer. J. Membr. Sci. 2014, 464, 8085. 